\title{
Evaluation Model of Core Competitiveness of Academic Journals Based on Analytic Hierarchy Process
}

\author{
Fei Qi ${ }^{1 *}$, Guanglei Meng ${ }^{2}$
}

\author{
${ }^{1}$ Journal of Shenyang Aerospace University, Shenyang Aerospace University,Shenyang,Liaoning, 110136,China; \\ ${ }^{2}$ College of Automation, Shenyang Aerospace University, Shenyang, Liaoning,110136, China \\ "Corresponding author. Email: qifeisunshine@ 163.com
}

\begin{abstract}
Evaluation of academic journals is a complicated decision-making problem. In order to improve the influence of academic journals, an evaluation model of core competitiveness of academic journals is proposed. Firstly, the indexes of five major evaluation systems are analyzed to obtain the core elements of academic journals evaluation. Secondly, the analytic hierarchy process is used to construct the evaluation model of the core competitiveness of academic journals and establish the judgment matrix. The weights of influencing factors are calculated and sorted according to their importance. Through several years of verification in "Journal of Shenyang Aerospace University", the model has good adaptability and practical effect.
\end{abstract}

Keywords: core competitiveness of academic journals, analytic hierarchy process, evaluation model, judgment matrix, paired comparison

\section{INTRODUCTION}

Core competitiveness was first proposed by American scholars C.K. Prahalad and G. Hamel in 1990 [1]. In 2002, domestic scholars began to introduce the concept into journal research [2]. In recent years, the discussion on the core competitiveness of journals mainly focuses on the constituent elements, influencing factors, model construction, etc.. For example: Wang Qiang studies the core competitiveness of academic journals from the perspective of constituent elements [3]; Cai Jianwei explores the specific ways to improve the core competitiveness of journals from the main influencing factors [4]; Wang Guanzhu discusses how to build the core competitiveness of journals from the perspective of cultural globalization [5]; Huang Yuexin studies how to improve the competitiveness of sci-tech journals under the market economic model [6].

The core competitiveness of academic journals is the result of multiple factors, so the evaluation of academic journals is a complex decision-making problem. In this paper, analytic hierarchy process is used in the research of core competitiveness of academic journals which provides a new research method.

\section{Core Competitiveness of Academic Journals}

\subsection{Data Sources}

At present, there are five influential evaluation systems of sci-tech journals in China: An Overview of Chinese Core Journals, Core journals of Chinese Humanities and Social Sciences, Chinese Science Citation Database, Chinese
Science and Technology Journal Citation Report, and Chinese Core Journals Selection Database. The index of the core journals published by these evaluation systems has become a standard to evaluate the quality of Chinese sci-tech journals. This paper analyzes the evaluation indexes of the five evaluation systems of sci-tech journals, and summarizes the components of the core competitiveness of journals.

There are 16 evaluation indexes such as picked quantity, awards in the Overview of Chinese Core Journals. The evaluation index system of Chinese Core Journals of Humanities and social sciences is composed of 3 1-level indexes, 10 2-level indexes and 24 3-level indexes. The Chinese Science Citation Database includes 18 evaluation indexes such as number of paper institutions and H-index; Chinese Science and Technology Journal Citation Report includes 24 evaluation indexes, such as authority factor, discipline diffusion index. Chinese Core Journals Selection Database includes 14 evaluation indexes, such as total downloads, ratio of funded papers, etc.

\subsection{Data Classification}

Based on the analysis of 119 evaluation indexes of five evaluation systems of sci-tech journals, the core competitiveness of academic journals can be summarized as academic competitiveness, organizational competitiveness and marketing competitiveness.

Academic competitiveness mainly includes academic planning ability, academic resource acquisition ability, academic response ability. The organization competitiveness mainly includes management ability and innovation ability. Marketing competitiveness mainly includes positioning ability and promotion ability. 
Compare the elements of the criteria layer, to obtain the judgment matrix $\mathrm{G}$.

$$
G=\left(\begin{array}{ccc}
1 & 4 & 6 \\
1 / 4 & 1 & 3 \\
1 / 6 & 1 / 3 & 1
\end{array}\right)
$$

By using the same method, the other elements of each case were graded, and the matrix A, B, and C were obtained.

$$
\begin{gathered}
\mathrm{A}=\left(\begin{array}{ccc}
1 & 3 & 5 \\
1 / 3 & 1 & 3 \\
1 / 5 & 1 / 3 & 1
\end{array}\right) \\
\mathrm{B}=\left(\begin{array}{cc}
1 & 5 \\
1 / 5 & 1
\end{array}\right) \quad \mathrm{C}=\left(\begin{array}{cc}
1 & 3 \\
1 / 3 & 1
\end{array}\right)
\end{gathered}
$$

Taking the matrix $\mathrm{G}$ as an example, the weight coefficients of each parameter in the matrix are calculated and demonstrated.

(1)Numerical matrix product of $1 / \mathrm{m}$ power line

$$
\begin{aligned}
& W_{1}=(1 \times 4 \times 6)^{\frac{1}{3}}=2.884 \\
& W_{2}=(1 / 4 \times 1 \times 3)^{\frac{1}{3}}=0.909 \\
& W_{3}=(1 / 6 \times 1 / 3 \times 1)^{\frac{1}{3}}=0.385
\end{aligned}
$$

(2)To calculate the sum of the above results

$$
\begin{aligned}
& \sum W_{\mathrm{i}}=W_{1}+W_{2}+W_{3} \\
& \sum W_{\mathrm{i}}=2.884+0.909+0.385=4.178
\end{aligned}
$$

(3)To calculate the importance of each parameter (or weighted coefficient)

$$
\begin{aligned}
& \bar{W}_{1}=\frac{W_{1}}{W_{\mathrm{i}}}=2.884 / 4.178=0.69 \\
& \bar{W}_{2}=\frac{W_{2}}{W_{\mathrm{i}}}=0.909 / 4.178=0.218 \\
& \bar{W}_{3}=\frac{W_{3}}{W_{\mathrm{i}}}=0.386 / 4.178=0.092
\end{aligned}
$$

\subsection{Consistency check}

Consistency tests must be carried out to ensure that the evaluation is scientific. If the test is passed, it indicates that the evaluation order of each factor is quite consistent; if not, it is necessary to reconstruct the paired comparison matrix.

(1)Find the product of the original matrix and the importance of distribution

$$
\begin{aligned}
& {\left[\begin{array}{ccc}
1 & 4 & 6 \\
1 / 4 & 1 & 3 \\
1 / 6 & 1 / 3 & 1
\end{array}\right]\left[\begin{array}{c}
0.69 \\
0.218 \\
0.092
\end{array}\right]=\left[\begin{array}{l}
X_{1} \\
X_{2} \\
X_{3}
\end{array}\right]} \\
& X_{1}=1 \times 0.69+4 \times 0.218+6 \times 0.092=2.114 \\
& X_{2}=1 / 4 \times 0.69+1 \times 0.218+3 \times 0.092=0.667 \\
& X_{3}=1 / 6 \times 0.69+1 / 3 \times 0.218+1 \times 0.092=0.28
\end{aligned}
$$

(2)The maximum eigenvalue of a matrix $\left(\lambda_{\max }\right)$ 


$$
\lambda_{\max }=\frac{1}{\mathrm{~m}}\left(\frac{x_{1}}{\bar{W}_{1}}+\frac{x_{2}}{\bar{W}_{2}}+\frac{x_{3}}{\bar{W}_{3}}\right)
$$

Based on the data obtained from the previous calculation

$$
\lambda_{\max }=1 / 3 \times\left(\frac{2.114}{0.69}+\frac{0.667}{0.218}+\frac{0.28}{0.092}\right)=3.056
$$

(3)To determine the average random consistency index (RI) The index is directly related to the number of matrices, that is, the number of parameters $(\mathrm{m})$. The specific values are shown in Table 2.

Table 2 Average random consistency index

\begin{tabular}{ccccccccccc}
\hline \hline $\mathrm{m}$ & 1 & 2 & 3 & 4 & 5 & 6 & 7 & 8 & 9 & 10 \\
\hline $\mathrm{RI}$ & 0 & 0 & 0.58 & 0.90 & 1.12 & 1.24 & 1.32 & 1.41 & 1.45 & 1.49 \\
\hline \hline
\end{tabular}

Calculating the random consistency $\mathrm{CR}$, if $\mathrm{CR}<0.1$ indicates that the judgment matrix has a satisfactory consistency. The calculation formula of $\mathrm{CR}$ is

$\mathrm{CR}=\mathrm{CI} / \mathrm{RI}=\left[\left(\lambda_{\max }-\mathrm{m}\right) /(\mathrm{m}-1)\right] / \mathrm{RI}$

The specific values substituted for

$\mathrm{CI}=(3.056-3) /(3-1)=0.028$

$\mathrm{CR}=0.028 / 0.58=0.048<<0.1$

It shows that the consistency of the above rating is good.

According to this calculation method, the matrix A, B and C are calculated, and the consistency of each matrix is $<0.1$.

\subsection{Ranking the importance of evaluation objects}

Calculate the impact of each parameter on the upper layer from the bottom layer of the model. The calculation method is to multiply the value of each parameter and the related factors of the upper layer, get the ranking of each parameter for the upper layer of the target. Through the calculation, we get the importance of different factors to the core competitiveness of academic journals. The influencing factors of the core competitiveness of academic journals are sorted as shown in Table 3 .

Table 3 Order of importance factors affect the core competitiveness of academic journals

\begin{tabular}{lll}
\hline \hline Order & \multicolumn{1}{c}{ Factor } & Weight \\
\hline 1 & academic planning ability $\left(\mathrm{C}_{1}\right)$ & 0.439 \\
\hline 2 & management ability $\left(\mathrm{C}_{4}\right)$ & 0.182 \\
\hline 3 & resources acquisition ability $\left(\mathrm{C}_{2}\right)$ & 0.178 \\
\hline 4 & academic response ability $\left(\mathrm{C}_{3}\right)$ & 0.072 \\
\hline 5 & positioning ability $\left(\mathrm{C}_{6}\right)$ & 0.069 \\
\hline 6 & innovation ability $\left(\mathrm{C}_{5}\right)$ & 0.036 \\
\hline 7 & promotion ability $\left(\mathrm{C}_{7}\right)$ & 0.023 \\
\hline \hline
\end{tabular}

\section{CONCLUSION}

Through the above research, we can get the evaluation model of the core competitiveness of academic journals and the importance of the various factors. This provides a scientific index system for the evaluation of academic journals. It's helpful for us to take measures to promote sustainable development of academic journals. This method has been applied to the guidance of Journal of Shenyang Aerospace University. In the past three years, the model has good adaptability and practical effect. The impact factors of journals increased from 0.327 in 2015 to 0.574 in 2018 .

\section{REFERENCES}

[1] Prahalad C K, Hamel Gary. The core competence of the corporation. Harvard Business Review.68(3)(1990) 79-91. https://doi.org/10.1007/3-540-30763-X_14

[2] Qian Zhao, Recognition of the core competitiveness of science and technology journals based on reader value, Chinese Journal of Scientific and Technical Periodicals, 22(3)(2011)410-413.DOI:CNKI:SUN:ZGCB.0.2011-12-0 13

[3] Qiang Wang. Research on the promotion of the core competitiveness of academic journals in Colleges. Youth Journalist, 16(8)(2019)31-32. DOI:

https://doi.org/10.15997/j.cnki.qnjz.2019.08.019

[4] Jianwei Cai. The exploration and practice of improving the core competence of journals by Chinese Physics B. Acta Editologica. 29(S2)(2017) 89-92.

\section{DOI: CNKI:SUN:BJXB.0.2017-S2-030}

[5] Guanzhu Wang. The construction of the core competitiveness of periodicals in the view of cultural globalization. Journal of Huanggang Normal University. 38(5)(2018)112-114.

[6] Yuexin Huang. On the Basis of Promoting Core Competitiveness of Sci-tech Periodical Publications. Management Observer.14(19)(2017) 58-59. https://doi.org/10.3969/j.issn.1674-2877.2017.10.022

[7] Haiyan Li, The path of ascension on the core competitiveness of periodicals from the "three sales" theory, A Vast View on Publishing.20(4) (2015)102-104. DOI:CNKI:SUN:CBGJ.0.2015-04-038

[8] Shuangquan Wen, College of Humanities and social sciences to enhance the core competitiveness of research, The Science Education Article Collects,11(8) 2015, pp.148-150. DOI:CNKI:SUN:KJXH.0.2015-08-070

[9] Nenggang Du, To explore the way to enhance the core competitiveness of sci-tech periodicals, Journal of Yangtze University. 37(8) (2014) 40-43. https://doi.org/10.3969/j.issn.1673-1395.2014.08.014 
[10] Li Zhang, Discussion on improving the comprehensive medical journal of core competency Journal of Huaihai Institute of Technology.12(12) (2016) 69-74.

https://doi.org/10.3969/j.issn.1671-0142.2016.02.012 